\title{
APRENDIZAGEM DAS CRIANÇAS E AULAS REMOTAS EM TEMPOS DE ISOLAMENTO SOCIAL DA COVID-Ig: INTERVENÇÃO DA PSICOTERAPIA COGNITIVO COMPORTAMENTAL
}

\author{
Aldinéia Brazão do Rosario ${ }^{1}$ \\ Francisrose Dias Miranda ${ }^{2}$ \\ Maria das Graças Teles Martins ${ }^{3}$
}

RESUMO: INTRODUÇÃO: A aprendizagem das crianças em tempos de isolamento social se apresenta fragilizada frente a epidemia da Covid-ı. Percebe-se que a saúde mental das crianças no contexto da pandemia, tem sido um ponto que chama a atenção de psicólogos, pesquisadores, professores educadores, profissionais de saúde, família e cuidadores. A Terapia Cognitivo Comportamental (TCC) apresenta intervenção terapêutica para amenizar o sofrimento psicológico e o ensino aprendizagem das crianças no contexto escolar. OBJETIVO: Discutir a aprendizagem das crianças do ensino fundamental em aulas remotas em tempos da Covid-ı́ e as contribuições da Terapia Cognitivo Comportamental na intervenção psicoterapêutica. METODOLOGIA: Fundamentada na revisão teórica da literatura com o método de pesquisa bibliográfica e exploratória. Os materiais foram livros, artigos científicos, periódicos, revistas e jornais disponíveis nas bases de dados: Capes, Idaam, SciELO, Fiocruz, OPAS/OMS, RBP e Unesco. RESULTADOS: Constatou-se que no isolamento social, as crianças podem ficar mais vulneráveis e dependentes, com dificuldades funcionais de desempenho e aprendizagem escolar. Existem manifestações inquietantes na área cognitiva, afetiva, emocional e comportamental expressos por meio de ansiedade, estresse, agitação, birras, agressividade, isolamento e timidez. CONSIDERAÇÕES FINAIS: O impacto do isolamento social imposto pela Covid-ı interferiu no comportamento e aprendizagem das crianças. A intervenção psicoterapêutica da TCC infantil volta-se para a redução dos sintomas, do sofrimento psicológico, da forma de interpretar a rotina que envolve modos de estudar e aprender, relacionamento social e afetivo frente aos colegas, escola e família. A TCC intervém com a ludicidade, criatividade, aprendizagem, na atenção, afeto, compreensão e fortalecimento visando o bem-estar físico, mental e social da criança.

Palavras-chave: Aulas Remotas. Covid-ı9. Crianças. Aprendizagem. Psicoterapia Cognitivo Comportamental

ABSTRACT: INTRODUCTION: Children's learning in times of social isolation is weakened by the Covid-ig epidemic. It is noticed that the mental health of children in the context of the pandemic has been a point that calls the attention of psychologists, researchers, educators, health professionals, families, and caregivers. Cognitive Behavioral Therapy (CBT) presents a therapeutic intervention to alleviate the psychological suffering and teaching and learning of children in the school context. OBJECTIVES: To discuss the learning of elementary school children in remote classes in the days of Covid-19 and the contributions of Cognitive Behavioral Therapy in psychotherapeutic intervention. METHODOLOGY: Based on the theoretical review of the literature using the bibliographic and exploratory research methods. The materials were

IAcadêmicas do roo Semestre do curso de Psicologia/Estácio de Macapá.

${ }^{2}$ Acadêmicas do 10 o Semestre do curso de Psicologia/Estácio de Macapá.

${ }^{3}$ Prof. Me. em Saúde Coletiva e Ciências da Educação/Estácio de Macapá. 
books, scientific articles, periodicals, magazines, and newspapers available in the databases: Capes, Idaam, SciELO, Fiocruz, PAHO/WHO, RBP, and Unesco. RESULTS: It was found that in social isolation, children can become more vulnerable and dependent, with functional difficulties in performance and school learning. There are disturbing manifestations in the cognitive, affective, emotional, and behavioral areas expressed through anxiety, stress, agitation, tantrums, aggressiveness, isolation, and shyness. FINAL CONSIDERATIONS: The impact of social isolation imposed by Covid-19 interfered in children's behavior and learning. The psychotherapeutic intervention of children's CBT is aimed at reducing symptoms, psychological suffering, the way of interpreting the routine that involves ways of studying and learning, social and affective relationships with peers, school, and family. CBT intervenes with playfulness, creativity, learning, attention, affection, understanding, and strengthening, aiming at the child's physical, mental and social well-being.

Keywords: Remote Lessons. Covid-19. Children. Learning. Cognitive Behavioral Psychotherapy.

\section{INTRODUÇÃO}

O objetivo deste estudo é discutir a aprendizagem das crianças do ensino fundamental em aulas remotas em tempos da Covid-ı e as contribuições da Terapia Cognitivo Comportamental (TCC) na intervenção. A pandemia da COVID-ı9 teve impacto global em diversos aspectos e como forma de prevenir o contágio da doença nesse período anormal, a OMS orientou o distanciamento social entre as pessoas (MÉDICI,

TATTO, LEÃO, 2020). Isso provocou diversas mudanças e atingiu várias áreas da sociedade, seja ela econômica, social e também educacional, pois, para ajudar a conter a propagação da doença, as escolas no mundo inteiro fecharam as portas. Uma das soluções mais debatidas nesse contexto pandêmico é a utilização de tecnologias digitais de comunicação e informação, uma vez que a utilização de ferramentas tecnológicas é um mecanismo que permite a ampliação das atividades humanas em todas as esferas sociais, sobretudo na educação. A Organização das Nações Unidas para a Educação, a Ciência e a Cultura (UNESCO), em um simpósio internacional sobre "Garantir o Direito à Educação Inclusiva de Qualidade para Pessoas com Deficiência: Do Compromisso à Ação”, em novembro de 2020, optou por apoiar o ensino e aprendizado à distância e inclusivo, como forma de mitigar os efeitos nefastos da pandemia que prejudica consideravelmente a igualdade de oportunidades para o progresso educacional e a aprendizagem ao longo da vida (UNESCO, 2020).

Este estudo se justifica pela relevância do tema na psicologia, educação, social, saúde mental e, principalmente na Psicoterapia cognitivo comportamental e áreas afins, 
em razão da situação atual de pandemia que traz impactos no cotidiano das crianças e adolescentes pois, interfere no desempenho e aprendizagem nas funções psicológicas relacionadas à socialização, lazer e desenvolvimento cognitivo com prejuízos significativos no emocional induzindo alto grau de estresse, ansiedade, irritabilidade, inquietações entre outros fatores. As motivações que conduziram a escolha por este tema foram trazer ao conhecimento dos professores educadores, profissionais de saúde, família e cuidadores, de que forma as aulas remotas interferem na aprendizagem das crianças em tempos de isolamento social. Além disso, sendo destacada a importância dos cuidados terapêuticos da psicologia direcionados para crianças afetadas emocionalmente em decorrência da crise causada pela COVID-I9, pois o isolamento social e a falta de contato com o ambiente escolar vieram a ser as principais causas do sofrimento emocional.

Diante disso, se faz o seguinte questionado: De que forma as aulas remotas interferem na aprendizagem das crianças em tempos de isolamento social? Quais as contribuições da Psicoterapia Cognitivo Comportamental na intervenção? Enfatiza-se que a prevenção e tratamento psicoterapêutico com crianças e adolescentes escolares são necessários considerando que se apresentam, na literatura, relatos em tempos de isolamento social de sintomas relacionados a ansiedade, estresse, irritabilidade e depressão sendo essencial prevenir danos à saúde física e mental. Desse modo, considera-se importante refletir de que forma as crianças interpretam as novas rotinas, modo de estudar, o trabalho dos pais e a criatividade da família em tempos de isolamento social? Como fazer de um ambiente único diversas utilidades com objetivo de atender as necessidades das crianças, a aprendizagem, as atividades escolares e familiares? Compreende-se que se tornam um ponto importante para que a escola, professores e psicólogos a busca de alternativas conjuntas para promover atividades individuais e coletivas com a finalidade para o desenvolvimento integral nos aspectos físico, psicológico, intelectual e social.

\section{METODOLOGIA}

Trata-se de uma revisão teórica da literatura, com o método de pesquisa bibliográfica e exploratória. Gil (2017), afirma que a pesquisa bibliográfica é elaborada a partir de material já publicado. As fontes utilizadas para desenvolver este estudo foram 
livros, artigos científicos, periódicos, revistas e jornais disponíveis nas bases de dados: Capes, Educação Interfaces Científicas, Faculdades Idaam, SciELO - Scientific Electronic Library, Fiocruz - Fundação Oswaldo Cruz, OPAS/OMS, RBP-Revista Brasileira de Psicoterapia, Unesco, publicados de 2004 a 2020. Além disso, busca-se materiais produzidos em 2021 que abordassem o público infantil e a pandemia da Covid-19. Nas questões históricas e relevantes à temática se fez uso de materiais anteriores ao aqui descrito.

Com relação aos critérios de inclusão exclusão, foram incluídos materiais que tinham relação com o tema abordado e continham as palavras-chave: "Crianças", "Aprendizagem", “Aulas remotas"; “Covid-I9"; "Psicoterapia Cognitivo Comportamental”. Com a finalidade de discutir a aprendizagem das crianças do ensino fundamental em aulas remotas em tempos da Covid-ı, com isolamento social, bem como as contribuições da psicoterapia cognitivo comportamental na intervenção. Nessa direção buscou-se ainda, caracterizar a aprendizagem de crianças do ensino fundamental, descrever a aprendizagem das crianças em tempos da Covid-ıg e isolamento social, bem como, identificar as contribuições da psicoterapia cognitivo comportamental na intervenção psicoterapêutica. Os materiais que não abordaram a temática foram excluídos.

Em relação a análise crítica dos riscos e benefícios, por se tratar de uma pesquisa com base na pesquisa bibliográfica e não envolver manipulação humana, não ocorreu a utilização do Termo de Consentimento Livre e Esclarecido (TCLE). Com relação aos aspectos éticos e legais este estudo está pautado de acordo com as Resoluções CNS - 466/12 e 510/2016. Este trabalho traz benefícios que possibilitam o cuidado da Psicologia e da Terapia Cognitivo Comportamental em crianças no ensino aprendizagem, com dificuldades de aprendizagem e vivencias em aulas remotas em tempos de isolamento social. Os benefícios deste estudo são considerados de relevância nas áreas da psicologia, Educação, da educação infantil, Psicoterapia cognitivo comportamental, social, saúde mental, além de trazer contribuições às diferentes áreas do conhecimento tornando-se nova fonte de informações para pesquisadores, acadêmicos de psicologia e, principalmente para as especialidades que tratam sobre aulas remotas, aprendizagem e educação infantil.

Com relação à análise dos dados deste estudo, após a coleta dos referenciais para fundamentação teórica, sucedeu-se uma construção teórica consubstanciada discutindo a aprendizagem das crianças do ensino fundamental em aulas remotas em tempos da Covid- 
I9 bem como descrevendo as técnicas e estratégias utilizadas pela Psicoterapia Cognitivo Comportamental na intervenção. Para Gil (2017), a análise dos dados é o nível de conhecimentos que o pesquisador dispõe sobre o assunto e o grau de precisão que são fatores relevantes para seu encadeamento. Nesse sentido, a construção de argumentação e discussão com base nos autores traz novas compreensões sobre o fenômeno estudado, além de contribuir com novas produções científicas. Teve-se como hipótese de que a pandemia da COVID-ı́ implicou grandes mudanças na vida das crianças e adolescentes, algumas delas foram a adaptação às aulas remotas e a convivência com a família em tempos de isolamento social. Que apresentam dificuldades e surgem em vários aspectos psicológicos como a ansiedade, estresse, irritabilidade, inquietação, dificuldades em aprender os conteúdos e lidar com aulas on-line. Insere-se ainda, a frustração de não ter prazer em estudar e a falta de apoio para ultrapassar os desafios cotidianos. As consequências são as alterações no comportamento, nas emoções, nos sentimentos que dificultam e interferem na aprendizagem. Considera-se que a psicoterapia cognitivo comportamental busca reduzir os sintomas estressores, de ansiedade, amenizar as dificuldades escolares e fortalecer a interação familiar, escolar e social.

\section{RESULTADOS E DISUSSÃO} 3.I Aprendizagem de crianças: desenvolvimento cognitivo, socialização e afeto

A Psicologia da Educação teve contribuições de importantes autores sobre a aprendizagem, tais como: as teorias de Jean Piaget, Lev de Vygotsky e Henri Wallon. Os conceitos desenvolvidos por esses autores são de grande relevância para o entendimento sobre como acontece o processo de aprendizagem. Conforme Piaget (1975) e a lógica do construtivismo, o conhecimento humano é construído graças à interação sujeito e meio, e o desenvolvimento intelectual-afetivo passa por etapas de organização, não sendo inato, nem apenas fruto de estimulações do ambiente. Em "O Nascimento da Inteligência na Criança", Piaget (1975) esclarece o sentido que dá a esses dois termos assimilação e acomodação e apresenta a seguinte explicação definidora:

$\mathrm{Na}$ assimilação: Piaget faz notar que a inteligência é assimilação na medida em que incorpora em seus quadros todos e qualquer dados da experiência. Para ele, quer se trate do pensamento que, graças ao juízo faz ingressar o novo no conhecido e reduz assim o 
universo as suas noções próprias. Reforça, afirmando, quer se trate da inteligência sensório-motora que estrutura igualmente as coisas percebidas, integrando-as nos seus esquemas, a adaptação intelectual abrange em qualquer dos casos, um elemento de assimilação, isto é, de estruturação por incorporação da realidade exterior a formas devidas à atividade do sujeito (PIAGET, 1975, p. 17). Na acomodação: Para o autor a vida mental também é acomodação ao meio ambiente. Explica que a assimilação nunca pode ser pura, visto que, ao incorporar novos elementos nos esquemas anteriores, a inteligência modifica incessantemente os últimos para ajustá-los aos novos dados. No entanto, inversamente, as coisas nunca são conhecidas em si mesmas, já que esse trabalho de acomodação, conforme Piaget, só é possível em função do processo inverso de assimilação (PIAGET, 1975, p. 18).

Constatou-se que a aprendizagem traz consigo a possibilidade de algo novo, incorporado a tudo que forma a vida do indivíduo, relacionando-se com a mudança dos conhecimentos que ele já possui. A aprendizagem teve como importantes contribuições a teoria Histórico-Cultural de Vygotsky. Este estudioso considera importante a influência da cultura na formação humana, e explicita: Quando observamos o curso do desenvolvimento da criança na idade escolar e o processo de sua aprendizagem, vemos efetivamente que toda matéria de ensino sempre exige da criança mais do que ela pode dar hoje, ou seja, na escola a criança desenvolve uma atividade que a obriga a colocar-se acima de si mesma. Pontua que isto sempre se refere a um sadio ensino escolar porque a criança começa a aprender a escrever quando ainda não observamos no curso do desenvolvimento da criança todas as funções que lhe assegurem a linguagem escrita. Vygotsky afirma que é por essa razão que a aprendizagem da escrita desencadeia e conduz o desenvolvimento dessas funções (VYGOTSKY, 20orb, p. 336 apud NUNES, SILVEIRA 2015, p. 54).

Entende-se que, para que a aprendizagem ocorra de forma significativa, é primordial a consideração dos conhecimentos que o aluno trás para a sala de aula, sua forma de compreender, seus interesses e vivências. A introdução de novos conceitos deve estar em sintonia com a realidade do aluno, com o seu contexto de existência, a fim de que ele possa dar sentido e significado aos conteúdos de estudo. As contribuições na aprendizagem da teoria de Wallon complementam o estudo do desenvolvimento da criança no ensino aprendizagem. A criança, para Wallon, é essencialmente emocional e gradualmente vai constituindo-se em um ser sociocognitivo. Este pesquisador e autor, 
estudou a criança contextualizada, como uma realidade viva e total no conjunto de seus comportamentos, suas condições de existência. Wallon considera que os processos emocionais e afetivos são relevantes no contexto da aprendizagem e esclarece: Existe uma conexão entre a emoção e o funcionamento da inteligência, sendo a primeira um fenômeno cuja função é mobilizar o outro, o que denota seu caráter socializador. A emoção é um elemento de expressão, que inclui aspectos orgânicos (tônicos/ musculares), ao qual o professor precisa estar atento. Quando o componente emocional é exacerbado, há uma tendência à inibição do componente intelectual, e vice-versa, o que pode dificultar a aprendizagem do aluno. (WALLON, 1989 apud NUNES, SILVEIRA, 2015, p.6o).

Para Galvão (200o), antes do surgimento da linguagem falada, as crianças comunicam-se e constituem-se como sujeitos com significado, através da ação e interpretação do meio entre humanos, construindo suas próprias emoções, que é seu primeiro sistema de comunicação expressiva. Estes processos comunicativos-expressivos acontecem em trocas sociais como a imitação. Imitando, a criança desdobra, lentamente, a nova capacidade que está a construir (pela participação do outro ela se diferenciará dos outros) formando sua subjetividade. Pela imitação, a criança expressa seus desejos de participar e se diferenciar dos outros constituindo-se em sujeito próprio. (GALVÃO, 2000 apud BASSO, 2010). Nesse sentido a socialização da criança inicia no contexto familiar em comunicação e trocas sendo aprimorado cada vez mais no contexto escolar e social. Ressalta-se que é importante a escola conduzir o aluno ao conhecimento levando em consideração suas emoções para que não haja interferência no processo de aprendizagem. As contribuições dos autores aqui descritos, são relevantes para a família, a escola e os profissionais da educação e psicologia desenvolverem um trabalho no âmbito educacional em diferentes perspectivas.

\subsection{Aprendizagem das crianças em tempos da covid-ıg e isolamento social}

Constata-se que o mundo vivencia uma graves problemas causados pela epidemia da Covid- 19 e as consequências são de mudanças na vida da sociedade com isolamento social. Nesse contexto, o isolamento social, vários setores foram atingidos entre eles as escolas com prejuízos no ensino aprendizagem das crianças e adolescentes. Frente a essa situação, vivenciamos coletivamente, o ensino remoto que se tornou a saída para que os 
alunos não deixassem de estudar. De acordo com a UNESCO (2020), mais de 1,5 bilhão de estudantes e jovens em todo o planeta estão sofrendo ou já foram afetados pelo impacto do fechamento de escolas e universidades devido à pandemia da COVID-ig.

Diante do exposto percebe-se que são grandes os desafios em toda sociedade, em todos os contextos e principalmente na educação, Cordeiro (2020) então afirma que os desafios são imensos, dentre eles, podemos destacar as ferramentas remotas que precisam ter parâmetros de qualidade, para que tenham maior eficácia. Ressalta-se que as desigualdades de acesso às tecnologias, são enormes, considerando-se que nem todas as crianças têm computador ou tablet conectados à internet. Contudo, o ensino remoto ainda é a melhor saída para minimizar o atraso no retorno às aulas presenciais (CORDEIRO, 2020, p. 3).

Enfatiza-se que o isolamento social traz a mudança de rotina e a falta de contato com o ambiente escolar sendo essas as principais causas do sofrimento emocional em crianças e adolescentes, pois é no ambiente escolar que as crianças aprendem, brincam e convivem, em relações que envolvem tentativas, derrotas, vitórias e riscos, no entanto, as dificuldades enfrentadas no processo ensino aprendizagem, durante as aulas remotas, são destacadas as crianças que não possuem a estrutura adequada. Desse modo, Alves (2020) descreve o quanto é preciso aprimorar a tecnologia na educação. A autora explica que distintos setores foram atingidos, incluindo as escolas que para os seus estudantes é vista como um importante espaço de socialização e intercâmbio entre seus pares. Faz notar que o contexto aqui apresentado torna-se preocupante, pois o processo que deveria ser prazeroso e rico, torna-se estressante, desgastante e frustrante para os sujeitos do processo de ensinar e aprender, incluindo nessa situação singular, os seus pais (ALVES, 2020, p. 360).

Registra-se que a Organização das Nações Unidas (ONU) manifesta preocupação com a saúde mental das crianças conforme aponta o Policy Brief: COVID-ı9 and the Need for Action on Mental Health (Resumo de Política: COVID-ıg e a Necessidade de Ação em saúde mental), publicado pela Organização Pan-Americana da Saúde (OPAS) e Organização Mundial da Saúde (OMS) (2020), que descreve o relato de pais espanhóis e italianos sobre o estado emocional e o comportamento de crianças afetadas com o confinamento, coforme dados a seguir: 
Figura I - Quadro da pesquisa publicada pela OPAS/OMS

\section{Parents' reports of children's difficulties during COVID-19 confinment (Italy and Spain)}

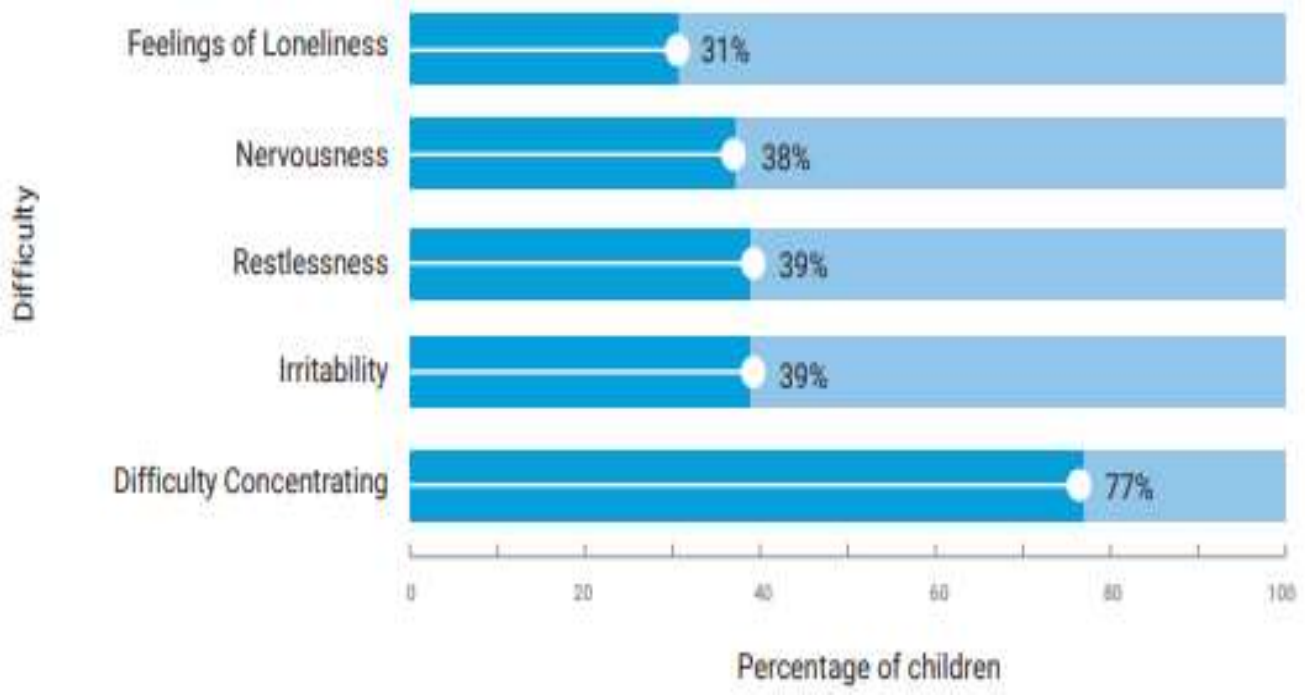

Fonte: OPAS/OMS, 2020 .

As informações apresentam percentuais de $31 \%$ sentimentos de solidão, $38 \%$ nervosismo, 39\% inquietação, 39\% irritabilidade e 77\% dificuldade de concentração. Nesse contexto, nota-se que o isolamento social já apresenta impactos negativos na vida das crianças e o que chama atenção é o alto índice de dificuldade de concentração, o que prejudica a aprendizagem durante as aulas remotas e em outros aspectos da vida. Reforçase que a saúde mental das crianças no contexto da pandemia, com o distanciamento e isolamento social torna-se ponto importante de atenção das famílias, professores e cuidadores e, logicamente dos profissionais de saúde, uma vez que a situação atual de pandemia se intensifica, amplia e interrompe a dinâmica do cotidiano das pessoas. Por esta razão, é necessário a realização de estudos que busquem formas de compreender os possíveis impactos desse período sobre as funções psicológicas, da saúde mental que afetam as crianças e adolescentes e, consequentemente, as possibilidades de intervenção terapêutica. Apesar das crianças serem menos contaminadas sintomaticamente pela COVID-I9, elas estão vulneráveis e podem ser mais afetadas no âmbito do desenvolvimento psicológico (LINHARES; ENUMO, 2020). 
Estes mesmos autores Linhares; Enumo (2020) esclarecem que medidas simples podem ser adotadas a fim de manter a estabilidade, estruturação e organização do ambiente doméstico, para se evitar o ambiente caótico e estressor e oferecer suporte e segurança às crianças. Demonstram que entre essas medidas tem-se como exemplo: estabelecer e manter horários, rotinas e tarefas no ambiente doméstico; dividir tarefas e responsabilidades entre os familiares; organizar os espaços possíveis em cômodos ou cantos com os materiais para as diferentes finalidades de atividades de trabalho, estudo e lazer; manter ativo o exercício da autonomia e controle realizando escolhas e tomadas de decisão no contexto do grupo familiar, sempre mediante a análise de alternativas possíveis; preservar os horários prazerosos de brincadeiras, conversas e leituras dirigidas para as crianças da casa.

Diversos autores entre eles, (Papalia; Olds; Feldman, 2010); (Linhares; Enumo, 2020); (Pureza et. al, 2014) e (Pereira Junior; Machado,2021) corroboram e reforçam que é necessário buscar estabelecer uma comunicação positiva com as crianças no sentido de atender às suas dúvidas e incertezas. Procurar ouvir com atenção comentários e expressão de sentimentos demonstrados por elas, buscar conversar sobre suas limitações e restrições necessárias do momento em que se sentem tristes e desmotivadas. É importante evitar os excessos de notícias e comentários negativos sobre o atual momento a fim de evitar impactos emocionais fortes e induzir medos e inseguranças. Por outro lado, compreender que nas crianças, por serem mais vulneráveis e dependentes, podem surgir ou acentuar-se algumas dificuldades funcionais tais como sono, alimentação e controle dos esfíncteres. Podem surgir, dificuldades comportamentais como agitação, birras, agressividade, isolamento e timidez.

Destaca-se a importância de refletir de que forma as crianças interpretam as novas rotinas, modo de estudar, o trabalho dos pais e a criatividade da família em tempos de isolamento social? Como fazer de um ambiente único diversas utilidades com objetivo de atender as necessidades das crianças, a aprendizagem, as atividades lúdicas, escolares e familiares? Compreende-se que se tornam um ponto importante tanto para a escola, professores e psicólogos, terapeutas infantis no sentido de buscarem alternativas conjuntas e ajuda mútua para promover atividades individuais e coletivas com a finalidade para o desenvolvimento integral nos aspectos físico, psicológico, intelectual e social. 
3.3 Intervenção cognitivo comportamental com crianças escolares no contexto da epidemia da covid-19

Inicialmente, considera-se pertinente discorrer um pouco sobre a Terapia Cognitivo Comportamental (TCC). A TCC teve início na década de 6o com Aaron Beck, neurologista e psiquiatra norte-americano. Ele propôs, inicialmente, um modelo cognitivo da depressão, posteriormente evoluiu com estudos para a compreensão de outros transtornos. De acordo com Knapp e Beck, (2008, p. 2) o modelo cognitivo foi originalmente construído de acordo com pesquisas conduzidas por Aaron Beck para explicar os processos psicológicos na depressão, em uma tentativa de provar a teoria freudiana de depressão como hostilidade retro fletida reprimida. Baseado em pesquisa sistemática e observações clínicas, Beck propôs que os sintomas de depressão poderiam ser explicados em termos cognitivos como interpretações tendenciosas das situações, atribuídas à ativação de representações negativas de si mesmo, do mundo pessoal e do futuro que denominou de tríade cognitiva.

Identifica-se que a composição da abordagem cognitivo comportamental tem em seu bojo diferentes modelos clínicos que sustentam protocolos psicoterapêuticos eficazes para uma variedade de quadros clínicos entre as quais estão ansiedade, estresse, depressão, TOC, fobias, transtornos sexuais, transtornos alimentares, entre outras psicopatologias, inclusive a aplicabilidade da TCC com crianças e adolescentes no TDAH, agressividade, ansiedade, fobia, estresse, etc., e atua em diferentes contextos clínicos, educacionais, organizacionais, sociais com diferentes públicos. Nas intervenções, salienta-se que existe três níveis de cognições que são identificados pela TCC, que são: pensamentos automáticos, crenças intermediárias e crenças centrais (A. BECK ET AL., 1997). Os pensamentos automáticos fazem parte de um fluxo de processamento cognitivo subjacente ao processamento consciente. Geralmente, são particulares ao indivíduo e ocorrem de maneira rápida através da avaliação do significado de episódios de sua vida (WRIGHT, BASCO, \& THASE, 2008).

Assim, tem-se a compreensão de que a Terapia Cognitivo Comportamental (TCC) se fundamenta em conceitos básicos do Modelo Cognitivo descrito por Beck, entre eles, pensamentos automáticos; crenças intermediárias; crenças nucleares. Pensamentos automáticos são conteúdos espontâneos que fluem na mente a partir de acontecimentos do 
dia a dia, as crenças intermediárias correspondem ao segundo nível de pensamento e refletem ideias ou entendimentos mais profundos que os pensamentos automáticos e ocorrem sob a forma de suposições ou regras, e as crenças centrais, seriam o nível mais profundo da estrutura cognitiva e compostas por ideias absolutistas, rígidas e globais que um indivíduo tem sobre si mesmo. (KNAPP \& COLS, 2004, p. 25; WRIGHT, BASCO, \& THASE, 2008).

Averiguou-se que, as crenças intermediárias correspondem ao segundo nível de pensamento e refletem ideias ou entendimentos mais profundos que os pensamentos automáticos e ocorrem sob a forma de suposições ou regras. Constituem uma forma que o indivíduo encontrou para reduzir o sofrimento provocado pelas crenças centrais. Essas crenças pressupõem que: "Desde que determinadas regras, normas e atitudes sejam cumpridas, não haverá problemas, e o indivíduo se mantém relativamente estável e produtivo. No entanto, se, por alguma circunstância esses pressupostos não estão sendo cumpridos, o indivíduo torna-se vulnerável ao transtorno emocional quando as crenças nucleares negativas são ativadas" (KNAPP \& COLS, 2004, p. 25; WRIGHT, BASCO, \& THASE, 2008).

Da mesma forma, entendeu-se que as crenças centrais seriam o nível mais profundo da estrutura cognitiva e compostas por ideias absolutistas, rígidas e globais que um indivíduo tem sobre si mesmo, as pessoas e o mundo. São incondicionais, isto é, independente da situação que se apresente ao indivíduo, ele irá pensar de modo consoante com suas crenças. Portanto, é primordial que no atendimento de crianças e adolescentes a intervenção terapêutica voltadas para essas crenças centrais ou nucleares que envolvem verdades absolutas relacionadas aos valores, normas, ideias centrais e cristalizadas que a pessoa tem sobre si mesmo, o mundo e os outros e que se formam ao longo de seu desenvolvimento. Para Knapp \& cols (2004; Wright, Basco, \& Thase, 2008) as crenças centrais vão se construindo e formando desde a infância nas experiências de aprendizado mais primitivas e são fortalecidas ao longo da vida até a fase adulta, moldando a percepção e a interpretação dos eventos, modelando o jeito psicológico de ser. Caso não haja ações corretivas dessas crenças centrais disfuncionais, o indivíduo irá considerá-las como verdades absolutas e imutáveis. 
Ao se discutir a aplicabilidade da Terapia cognitiva com crianças e adolescentes escolares, evidencia-se que nesse contexto de epidemia da Covid-I9, com distanciamento e isolamento social, as crianças precisam ser observadas cuidadosamente pelos pais e familiares no que diz respeito aos afetos, sentimentos, emoções e ao comportamento, pois as aulas remotas, o distanciamento social e o excesso de informações podem provocar interferências na aprendizagem além de prejudicar a saúde mental. Deste modo, considera-se, conforme Pereira Junior e Machado (202I), que é nesse momento escolar que as crianças começam a interagir e descobrir o mundo a sua volta, fora do seu ambiente familiar, fazendo amigos e aprendendo a conviver e respeitar as diferenças culturais. Portanto, o ambiente escolar da educação infantil é o primeiro local em que as crianças terão contatos fora de suas zonas de conforto e passarão a socializar com outras crianças e adultos de forma mais intensa e frequente, (PEREIRA JUNIOR; MACHADO, 202I)

No que diz respeito a intervenção da TCC no contexto clinico infantil, Pureza et. al (2014), esclarece que o trabalho do terapeuta na TCC com crianças e adolescentes inicia antes da chegada do paciente. O terapeuta, antecipadamente, inicia na preparação da sala $e$ na eleição dos brinquedos. A sala busca contemplar vários cuidados básicos, entre eles, um banheiro, por exemplo, além dos brinquedos variados que podem ser utilizados e que possam auxiliar a criança em processos de expressão entre eles estão, por exemplo, desenhos e argilas. Esta autora enfatiza que para os processos de identificação pode ser utilizado brinquedos como bonecos da família, animais e outros personagens, além de jogos estruturados tanto cooperativos quanto competitivos, que permitem a avaliação dos processos da criança.

Registra-se que pode ser interessante também a presença de brinquedos úteis para metáforas no trabalho de reestruturação cognitiva tais como lentes de aumento, óculos, balanças, entre outros. É importante, ao iniciar o atendimento, sempre verificar a preferência e história da criança, de modo a adaptar os materiais e brinquedos antes da sessão. O terapeuta deve verificar também como a criança é capaz de entender a lógica das coisas, mas seu pensamento ainda está em desenvolvimento, recursos para representação concreta dos conceitos também são necessários (OLIVEIRA et.al apud OLIVEIRA; ANDRETA ORG., 2012). 
Dessa maneira, os autores fazem notar que é fundamental que, na primeira sessão com a criança, os pais sejam orientados a explicar para ela o porquê de ela estar indo a um

psicoterapeuta. É aconselhável incluir toda a família no problema, de modo a eliminar o aspecto punitivo do tratamento e possibilitar adesão eficaz no processo psicoterápico. A partir dessa primeira sessão, conforme a demanda e o diagnóstico da criança, serão aplicadas as técnicas cognitivas e comportamentais, conforme ensinam (PUREZA et. al, 2014). É pertinente e necessário o terapeuta entender a queixa ou dificuldade que a criança expressa, além de ter contato com a escola, com o(a) professor(a), para saber como a criança se desenvolve no ensino aprendizagem, na ludicidade, na interação social, etc. Compreende-se que o ato de brincar constitui para a criança um fator importante no desenvolvimento infantil uma vez que traz repertórios de desenvolvimento cognitivo, social, biológico, motora e afetiva.

Pereira Junior e Machado (202I), reforçam que no ambiente escolar, professores, familiares, responsáveis e qualquer um que seja responsável por uma criança pequena têm quebrado a cabeça para proporcionar diversos tipos de atividades lúdicas que instiguem a criança durante esse processo de isolamento social, pois é gigantesco o desafio de se realizarem atividades lúdicas como jogos e brincadeiras através dos smartphones, tablets e computadores a distância com crianças em pré-escolas e creches. Dado que, para as crianças pequenas presentes nesses segmentos de ensino, os jogos são atividades de reconhecimento de espaço, objetivos e lógica das brincadeiras. Dessa maneira, familiares e responsáveis passarão a ser vistos como mediadores nas rotinas diárias das tarefas escolares e terão a oportunidade de participar de forma ativa na educação da criança. (PEREIRA JUNIOR; MACHADO, 202I).

$\mathrm{Na}$ Terapia cognitivo comportamental com crianças e adolescentes, a ansiedade, o estresse, a agressividade, irritabilidade estão presentes em tempos de isolamento social da epidemia da Covid-ı9. Portanto tem sua expressão em quatro dimensões: emoções, comportamento, pensamentos e o corpo. A intervenção deve abarcar, portanto, as dimensões comportamental, cognitiva, emocional e social. No âmbito do tratamento isso ocorrerá através de práticas, recompensas, tarefas para casa, observação do processamento da informação, nomeação de sentimentos e participação dos pais, familiares e pares. 
Com relação à prática da avaliação infantil na Terapia Cognitivo Comportamental diferentes autores corroboram que deve ser levado em conta alguns aspectos tais como: a) identificação e compreensão das queixas da criança e/ou do adolescente e b) processo de conceitualização cognitiva. Os porta-vozes das queixas e sintomas são geralmente os pais e/ou cuidadores. Por esta razão, torna-se importante a realização de uma completa entrevista de anamnese, uma vez que é por meio desse processo que se obtém uma melhor compreensão de aspectos emocionais (vínculos estabelecidos, humor prevalente, como reage às diversas situações vivenciadas), psicossociais (relacionamento familiar, interpessoal, acadêmico) e que são planejados e direcionados futuros procedimentos. A prática clínica da TCC demonstra que, quanto mais completa for a anamnese a respeito da criança e do adolescente, melhor será o planejamento e a condução do caso. Portanto, essa etapa da avaliação infantil permite a utilização de escalas e questionários a serem respondidos pelos pais e, muitas vezes, pela própria criança, professor ou outro profissional específico que tenha contato direto com a mesma (BECK, 2013; BUNGE; GOMAR; MANDIL, 20I2; PETERSEN; WAINER, 20II).

\subsubsection{Estratégias e Técnicas de Intervenção Cognitivo Comportamental com crianças e adolescentes}

Para a realização das intervenções cognitivo comportamentais da TCC com crianças e adolescentes, os terapeutas poderão fazer uso de diferentes técnicas e estratégias na clínica infantil, objetivando a redução dos sintomas, promover a expressão de afetos, sentimentos e comportamentos que induzem à ansiedade, estresse, pânico, fobias etc. Nesse sentido, apresentam-se, a seguir, algumas técnicas e estratégias utilizadas pelos diferentes autores como contribuições para este estudo:

Baralho das emoções: Caminha e Caminha (2008) desenvolveram o Baralho das Emoções com o objetivo de ajudar as crianças a conhecer e identificar as emoções. $\mathrm{O}$ baralho das emoções é formado por 24 cartas, cada uma contendo a expressão de uma emoção. Entre elas estão incluídas seis cartas com as emoções básicas, ou seja, as primeiras emoções sentidas desde muito pequeno, que são o amor, a tristeza, a alegria, a raiva, o medo e o nojo. Essas emoções vão se estendendo para emoções mais complexas ao longo do desenvolvimento da criança, (PAPALIA; OLDS; FELDMAN, 20ı0). 
Relógio dos Pensamentos-Sentimentos: trata-se de uma técnica que pode ser utilizada para ajudar as crianças a identificarem suas emoções e também seus pensamentos. Esse relógio é feito durante a sessão juntamente com o paciente, e no lugar dos números o paciente vai desenhar pequenos rostos representando as emoções. A ideia é ajudar a criança a perceber e entender seus sentimentos e mostrar a ela que as emoções mudam e passam assim como mudam as horas. Através dos ponteiros, a criança pode indicar o que está sentindo naquele momento, e o terapeuta pode ajudá-la a identificar que pensamentos a estão levando a sentir-se assim daquela forma (FRIEDBERG; MCCLURE, 2004).

Psicoeducação: é uma técnica tem a importante função de orientar o paciente quanto a seu funcionamento, diagnóstico, sintomas e sobre o próprio tratamento, facilitando o processo de mudança. $\mathrm{Na}$ psicoterapia infantil, a técnica da psicoeducação pode ser utilizada tanto com os pais quanto com a própria criança. A forma como será feita obedecerá a idade e o grau de desenvolvimento em que o paciente se encontra. Pode ser utilizada, com crianças menores, uma Psicoeducação Indireta na qual se utiliza como meios as metáforas, de histórias ou de personagens que não se refiram diretamente a elas. O contato com histórias é comum na infância, o que faz com que as crianças se sintam à vontade lidando e conversando sobre histórias e contos (FRIEDBERG; MCCLURE; GARCIA, 2OII).

Friedberg et. al (20II) explicitam que as técnicas comportamentais também são bastante utilizadas no tratamento com crianças e adolescentes. Levando-se em consideração a idade e a demanda da criança, que pode apresentar mais dificuldades em prestar atenção em suas cognições e monitorá-las do que os adultos, sendo preferível a utilização de intervenções comportamentais. Assim, as técnicas comportamentais podem reduzir a intensidade e frequência dos comportamentos disfuncionais e aumentam os comportamentos desejados. Ressalta-se que várias outras técnicas cognitivo comportamentais podem ser utilizadas no atendimento de crianças e adolescentes, entre elas temos as técnicas de relaxamento que são úteis a pacientes com diferentes demandas, principalmente em pacientes ansiosos, pois, além dos processos psicológicos, essas técnicas influenciam em respostas fisiológicas que atuam sobre os sintomas físicos da ansiedade 
(FRIEDBERG; MCCLURE; GARCIA, 20II). Apresentam-se algumas técnicas úteis na intervenção:

Relaxamento muscular progressivo: Esta técnica para ser utilizada com crianças, ela deve ser adaptada para que se obtenha uma maior adesão do paciente. É uma técnica de contração muscular e relaxamento por essa razão requer algumas adaptações como por exemplo, imaginar o corpo rígido como um robô, depois mole como um boneco de pano e em seguida pedir que a criança descreva como se sentiu em cada uma das vezes (PETERSEN et. al., 20II).

Treino de Respiração Diafragmática: é uma técnica que ajuda no relaxamento e é indicado que o paciente inspire e expire de forma lenta e profunda. Com as crianças, podem ser utilizadas bolhas de sabão, pois, para que as bolhas se formem, deve-se assoprar de forma lenta, o que ajuda na regularização da respiração e distração dos sintomas físicos ocasionados pela ansiedade. As bolhas de sabão também podem ser utilizadas com crianças que tenham dificuldade de tolerar frustrações, o que gera irritação e raiva (ZANONATO; PRADO, 2012).

Torna-se importante entender que quando se realiza trabalhos com crianças, devese levar em conta a idade em que se encontra e a etapa do seu desenvolvimento para que se possa escolher a técnica ou intervenção mais adequada. Alguns estudos trazem a constatação de alterações comportamentais em crianças tais como: sentimentos de solidão, nervosismo, inquietação, irritabilidade e dificuldade de concentração durante o período das aulas remotas. Dessa maneira, enfatizam a importância da intervenção da psicoterapia cognitivo comportamental no tratamento. Evidenciou-se com base nos autores Cordeiro e Alves (2020), que as dificuldades enfrentadas ocorrem por falta de estrutura adequada, o que deixa as crianças em desigualdade no acesso as aulas, além do prejuízo pela falta do contato social. Os autores Piaget, Vygotsky e Wallon afirmam que a convivência social constitui fator primordial no contexto da aprendizagem, e durante o período pandêmico as crianças e estudantes foram privados de vivenciar essa experiência tão rica e prazerosa. Nesse contexto da Covid-ı9, evidenciou-se alterações comportamentais, emocionais e cognitivas nas crianças escolares. A TCC busca intervir com eficácia na psicoterapia infantil. 
Acrescenta-se, no campo de aprendizagem educativa, as contribuições de Pereira Junior e Machado (2021) quando explicitam que inúmeros professores da educação infantil também estão passando por um momento incomum e bastante desafiador no ambiente educacional em tempos de isolamento social. Estes mesmos autores apresentam algumas orientações dadas pelos sites Jornada Edu e Diário Escola como contribuições de orientação aos professores que consideramos importante apresentar aqui. Estas orientações incluem:

- Enviar vídeos curtos: Crianças não devem passar muito tempo em frente a telas. Mesmo os mais importantes vídeos devem ser rápidos, claros e objetivos.

- Produzir material assertivo: Os pequenos perdem o interesse rapidamente, clareza e objetividade são fundamentais na educação remota de crianças.

- Propor atividades factíveis: As atividades sugeridas devem ser possíveis de serem realizadas com objetos e materiais encontrados em casa.

- Vídeos de psicomotricidade: Vídeos curtos com atividades de psicomotricidade, coordenação motora fina, coordenação global etc. Podem ser repetidos muitas vezes, em casa.

- Vídeos para aproximar: Para manter a proximidade com os alunos, disponibilize vídeos com as músicas da entrada das aulas, da hora do lanche e do almoço. Assim, os pequenos não perdem o laço afetivo com os professores.

- Atividades extras: A coordenação pode enviar vídeos com os passinhos novos da aula de balé, alguns movimentos da aula de capoeira, palavrinhas de inglês, por exemplo. No processo de Educação remota de crianças, solicite aos pais que filmem seus filhos e, até, façam com eles as atividades.

- Experiências científicas: Proponha uma aula de ciências para os alunos entre 4 e 5 anos: a experiência do feijão. Crie um kit de ciências com um copo de plástico, três grãos de feijão, um chumaço de algodão e envie aos pais. Essa é uma maneira das crianças acompanharem o nascimento de uma vida e de interação, na qual toda a família pode participar.

- Interação na Educação remota de crianças: Enviar fotos do ambiente escolar: do jardim, da pracinha, do refeitório, da sala de musicalização, da sala de aula... Também, dos profissionais da escola, da professora, da recepcionista, dos cuidadores, da pessoa 
que faz a limpeza, da cozinheira e da direção, por exemplo. A tarefa é pedir que a criança mostre aos pais os lugares que ela mais gosta, que fale o nome das pessoas, que conte o que lembra e do que tem saudades.

No atendimento interventivo da TCC com crianças, percebe-se que as orientações psicoeducativas são essenciais para as crianças, pais e familiares que corroboram com tudo o que foi descrito neste estudo. Evidencia-se que, apesar de poucos estudos a respeito das consequências do isolamento social para crianças e, de acordo com a Fiocruz (2020) o impacto da pandemia na infância tem efeitos diretos e indiretos. Os efeitos diretos dizem respeito às manifestações clínicas da COVID-19, os efeitos indiretos são vários, dentre os quais podemos citar: prejuízos no ensino e aprendizagem, na socialização, no desenvolvimento cognitivo, o afastamento do convívio familiar e dos amigos, o estresse (e sua toxicidade associada), tais efeitos afetam enormemente a saúde mental de crianças e adolescentes, gerando um claro aumento de sintomas de depressão e ansiedade.

Observou-se que as emoções, os afetos, a cognição e comportamentos podem variar de acordo com a maneira como cada criança interpreta uma situação pois, é o eixo central da abordagem cognitivo comportamental, que estuda as relações que se estabelece com o ambiente externo e interno através de processos cognitivos, afetivos e comportamentais, bem como as relações estabelecidas entre esses processos, buscando compreender o sofrimento em toda sua complexidade.

A psicoterapia com crianças é uma área que vem tendo interesse pelos profissionais de psicologia nos últimos anos, especialmente no âmbito de promoção e prevenção de saúde. O tratamento psicológico de crianças e adolescentes tem sido considerado não apenas como uma medida terapêutica, mas principalmente como uma forma de prevenção de doenças mentais e de promoção de saúde. Soma-se também a esses fatos o movimento em defesa e de valorização de diagnósticos precoces na infância visando a tratamentos mais eficazes e prevenção de psicopatologias na vida adulta (DELPRETE; DELPRETTE, 2005); (PETERSEN e WAINER, 20II); (PUREZA, 2014).

Entende-se que o desenvolvimento do tratamento não depende somente do conjunto de técnicas e estratégias selecionadas, mas, a sensibilidade dos terapeutas infantis é um fator muito significativo. Algumas variáveis são significativas e devem ser observadas na avaliação inicial: as comorbidades, o nível de desenvolvimento, estressores 
familiares e ambientais e, finalmente, a condição socioeconômica. Considera-se importante o ajuste da fina sintonia entre fidelidade às técnicas que mostram efetividade $e$ flexibilidade indispensável a um terapeuta no atendimento principalmente, em tempos de covid-ı9 cujas demandas são intensas. O terapeuta da TCC deve ser habilidoso e com boa formação, capaz de individualizar a proposta observando a subjetividade de cada criança com empatia, acolhimento, respeito e consideração, extensivo aos pais, professores e cuidadores.

Evidenciam-se que o trabalho psicoterápico infantil além de ter a participação efetiva dos pais, fator indispensável na TCC com crianças, é importante que entendam que sua participação é ativa no tratamento a fim de compreender a intervenção, acompanhar e auxiliar no melhor desempenho da criança e do adolescente no processo. Além disso, por ser um fator de fortalecimento e de sucesso no tratamento, é primordial o vínculo do terapeuta com os pais. Os pais são a principal fonte de dados e agentes de mudanças na vida da criança, (PETERSEN E WAINER, 2oII); FREDBERG E MCCLURE, 20II); (PUREZA, 2014)

\section{CONSIDERAÇÕES FINAIS}

Buscou-se neste estudo discutir a aprendizagem das crianças do ensino fundamental em aulas remotas em tempos da Covid-ı́ e as contribuições da Terapia Cognitivo Comportamental (TCC) na intervenção. Conclui-se que o estudo alcançou os objetivos que se propôs e que a problemática levantada foi contemplada. Descreve-se os impactos causados pela epidemia da Covid-19 com o isolamento social e o processo de aprendizagem das crianças, a importância do convívio social, além dos prejuízos evidenciados pelas autoridades e pesquisadores a respeito dos danos diretos e indiretos na vida das crianças.

$\mathrm{Na}$ aprendizagem destaca-se as contribuições das teorias de Jean Piaget, Lev de Vygotsky e Henri Wallon e os conceitos desenvolvidos por esses autores para o entendimento sobre como acontece o processo de aprendizagem. Piaget (1975) afirma que o conhecimento humano é construído graças à interação sujeito e meio, e o desenvolvimento intelectual-afetivo passa por etapas de organização, não sendo inato, nem apenas fruto de estimulações do ambiente. Enfatiza a importância da assimilação e acomodação no processo de aprendizagem. Henri Wallon afirma que os processos emocionais e afetivos 
são relevantes no contexto da aprendizagem e destaca a existência de uma conexão entre a emoção e o funcionamento da inteligência pois, quando o componente emocional é exacerbado, há uma tendência à inibição do componente intelectual, e vice-versa, o que pode dificultar a aprendizagem do aluno. (WALLON, 1989 apud NUNES, SILVEIRA, 2015, p. 6o).

As contribuições de Cordeiro (2020, p. 3); Pereira Junior; Machado, (2021) retratam que os desafios são imensos, dentre eles, as ferramentas remotas que precisam ter parâmetros de qualidade, para que tenham maior eficácia, e as desigualdades de acesso às tecnologias, são enormes, uma vez que nem todas as crianças têm computador ou tablet conectados à internet. Linhares; Enumo (2020) afirmam ser importante buscar estabelecer uma comunicação positiva com as crianças no sentido de atender às suas dúvidas $e$ incertezas. Fazem notar da necessidade de ouvir com atenção comentários e expressão de sentimentos expressos pelas crianças, conversar sobre suas limitações e restrições necessárias do momento. Podem surgir, dificuldades comportamentais como agitação, birras, agressividade, isolamento e timidez.

Salienta-se que durante a primeira infância as emoções começam a se desenvolver juntando-se a formação da personalidade. Assim evidenciou-se as contribuições de diversos autores que explicitam sobre intervenção da TCC com crianças entre eles Pureza et. al (2014) e Oliveira et.al apud Oliveira (2012). As intervenções cognitivo comportamentais com crianças e adolescentes corrobora o uso de diferentes técnicas e estratégias da TCC, objetivando a redução dos sintomas, a expressão de afetos, sentimentos e comportamentos. Registra-se as contribuições de várias técnicas e estratégias cognitivo comportamentais tais como: baralho das emoções, relógio dos pensamentos e sentimentos, psicoeducação, relaxamento muscular progressivo e treino de respiração diafragmática descritas por CAMINHA E CAMINHA (2008), FRIEDBERG E MCCLURE (2004), FRIEDBERG, MCCLURE E GARCIA (20II), PETERSEN ET. AL. (20II) E ZANONATO E PRADO (2012).

É importante destacar a eficácia da intervenção da psicoterapia cognitivo comportamental e os resultados positivos no tratamento com crianças, com foco na ludicidade, criatividade e aprendizagem. Pereira Junior; Machado, (202I) indicam orientações aos professores na dinâmica do ensino remoto com atividades diferenciadas 
focadas na ludicidade, expressão corporal, ciência etc. e o envolvimento dos das crianças, pais pares e família. Diante de tudo o que foi exposto, argumenta-se que este estudo é relevante em todas as áreas da ciência, principalmente nas áreas da educação, saúde mental, psicologia clínica, terapia cognitivo comportamental, bem como informação valiosa para profissionais da educação, pais e os cuidadores de crianças em tempos de epidemia da Covid-ıg e pós pandemia. Portanto, a intervenção psicológica, e a psicoterapia cognitivo comportamental são indispensáveis para que seja assegurado as crianças e adolescentes o bem-estar físico, mental e social a fim de amenizar o sofrimento psicológico e melhorar a qualidade de vida e a aprendizagem escolar.

\section{REFERÊNCIAS BIBLIOGRÁFICAS}

ALVES, Lynn. Educação remota: entre a ilusão e a realidade. Interfaces CientíficasEducação, v. $8, \quad$ n. 3 , p. 348-365, 2020. Disponível em: https://periodicos.set.edu.br/educacao/article/view/925I. Acesso em: 4 mar. 202I.

BASSO, Cintia Maria. Algumas reflexões sobre o ensino mediado por computadores. (2010) Disponível em: http://coral.ufsm.br/lec/o2_oo/Cintia-L\&C4.htm. Acesso em I2 dez. 202I.

BECK, Judith S. Terapia cognitivo-comportamental. Porto Alegre: Artmed Editora, ed. 2, 2014 .

BECK, J. S. Terapia cognitiva: teoria e prática. Porto Alegre: Artmed; 2013.

BUNGE, E.; GOMAR, M.; MANDIL, J. Terapia cognitiva com crianças e adolescentes: Aportes técnicos. São Paulo: Casa do Psicólogo, v. 306, 2012.

CAMINHA, Renato Maiato; CAMINHA, Marina Gusmão. Baralho das emoções: acessando a criança no trabalho clínico. Porto Alegre: Sinopsys, 2008.

CORDEIRO, Karolina Maria de Araújo. O Impacto da Pandemia na Educação: A Utilização da Tecnologia como Ferramenta de Ensino, p. 3, 2020. Disponível em: http://repositorio.idaam.edu.br/jspui/handle/prefix/II57. Acesso em: II mar. 202I.

DEL PRETTE, Z. A. P; DEL PRETTE A. D. A importância das habilidades sociais na infância. In: DEL PRETTE Z. A. P; DEL PRETTE A. D; SOUZA M.C. Psicologia das habilidades sociais na infância: teoria e prática. Petrópolis: Vozes; 2005. 
FIOCRUZ, COVID-ıя e a Saúde da Criança e do Adolescente, Rio de Janeiro, 2020. Disponível em: http://www.iff.fiocruz.br/pdf/covidi9_saude_crianca_adolescente.pdf. Acesso em: 03 maio 2021.

FRIEDBERG R.D; MCCLURE J.M. A prática clínica de terapia cognitiva com crianças e adolescentes. Porto Alegre: Artmed; 2004.

FRIEDBERG R.D; MCCLURE J.M; GARCIA J.H; Técnicas de terapia cognitiva para crianças e adolescentes: ferramentas para aprimorar a prática. Porto Alegre: Artmed; 2011.

GIL, Antônio Carlos. Como Elaborar Projetos de Pesquisa. - 6. ED - Atlas 2017. GALVÃO, Izabel., HENRI WALLON: Uma concepção dialética do desenvolvimento infantil. 7 $7^{\text {a }}$.ed. Petrópolis, RJ : Vozes, 200o.(Educação e conhecimento).

KNAPP, Paulo; BECK, Aaron T. Fundamentos, modelos conceituais, aplicações e pesquisa da terapia cognitiva. Brazilian Journal of Psychiatry, v. 30, p. s54-s64, 2008. Disponível em: https://www.scielo.br/j/rbp/a/HLpWbYk4bJHY39sfJfRJwtn/. Acesso em: I5 mai. 2021.

LINHARES, Maria Beatriz Martins; ENUMO, Sônia Regina Fiorim. Reflexões baseadas na Psicologia sobre efeitos da pandemia COVID-19 no desenvolvimento infantil. Estudos de Psicologia (Campinas), v. 37, 2020. Disponível em: https://www.scielo.br/j/estpsi/a/CrYD84R5ywKWBqwbRzLzd8C. Acesso em: i7 mai. 2021.

MÉDICI, Mônica Strege; TATTO, Everson Rodrigo; LEÃO, Marcelo Franco. Percepções de estudantes do Ensino Médio das redes pública e privada sobre atividades remotas ofertadas em tempos de pandemia do coronavírus. Revista Thema, v. I8, p. 136-155, 2020. Disponível http://periodicos.ifsul.edu.br/index.php/thema/article/viewFile/1837/1542. Acesso em: 02 abr. 202I.

NUNES. A; SILVEIRA. R. Conceituação, estratégias e concepções de aprendizagem - 3. ed. rev. - Fortaleza: Ed UECE, 2015. 122. Disponível em: https://educapes.capes.gov.br/bitstream/capes/431616/2/Livro_Psicologia\%2oda\%20Apre ndizagem.pdf. Acesso em: II abr. 202I.

OlIVEIRA, A. L; NASCIMENTO, A. C. A; DUQUE, F. M. (Organizadoras). Psicoterapia Infantil On-line: Técnicas e Ferramentas desenvolvidas durante a pandemia da Covid-r9. Ed. UNITAU, Taubaté: SP, 2020. Disponível em: http://186.236.83.17:8080/jspui/bitstream/20.500.11874/4005/r/ISBN9786586914399.pdf.

Acesso em: I5 mai. 2021.

OLIVEIRA R.G; SOARES S.C. Terapia cognitivo-comportamental para crianças. In: OLIVEIRA M.S; ANDRETTA, I. organizadores. Manual prático de terapia cognitivocomportamental. São Paulo: Casa do Psicólogo, p. 467-48o, 2012. 
Organização Pan-Americana da Saúde - OPAS/OMS Brasil - ONU destaca necessidade urgente de aumentar investimentos em serviços de saúde mental durante a pandemia de COVID-19 - Policy Brief: COVID-19 and the Need for Action on Mental Health, p. 12, 2020.

https://www.paho.org/bra/index.php?option=com_content $\&$ view =article\&id=6r70:onudestaca-necessidade-urgente-de-aumentar-investimentos-em-servicos-de-saude-mentaldurante-a-pandemia-de-covid-I9\&Itemid=839. Acesso em: 17 abr. 202I.

PAPALIA, D. E; OLDS S.W; FELDMAN R. D. Desenvolvimento humano. Porto Alegre: AMGH, zoio.

PEREIRA JUNIOR, Lucimar da Silva; MACHADO, Joana Bartolomeu. Educação Infantil em tempos de pandemia: desafios no ensino remoto emergencial ao trabalhar com jogos e brincadeiras. Revista Educação Pública, v. 2I, no 6, 23 de fevereiro de 2021. Disponível em: https://educacaopublica.cecierj.edu.br/artigos/21/6/educacao-infantil-em-tempos-depandemia-desafios-no-ensino-remoto-emergencial-ao-trabalhar-com-jogos-e-brincadeiras.

Acesso em: 12 dez. 2021.

PETERSEN, C. S; WAINER R. Princípios básicos da terapia cognitivo-comportamental de crianças e adolescentes. In: PETERSEN C.S; WAINER R. organizadores. Terapias cognitivo-comportamentais para crianças e adolescentes. Porto Alegre: Artmed, p. I6-3I, 2011 .

PETERSEN, C. S; BUNGE, E; MANDIL, J; GOMAR, M. Terapia cognitivocomportamental para os transtornos de ansiedade. In: PETERSEN C.S; WAINER R. Terapias cognitivo-comportamentais para crianças e adolescentes: ciência e arte. Porto Alegre: Artme, p. 232-55, 2011.

PIAGET, J. O Nascimento da inteligência na criança 2. ed. Rio de Janeiro: Zahar; Brasília:INL,I975. em: http://dinterrondoniazoio.pbworks.com/f/O+nascimento+da+intelig\%C3\%AAncia+na+cr ian\% $\mathrm{C}_{3 \% \mathrm{~A}}$ 7a.pdf. Acesso em: ir abr. 202I.

PUREZA; J. R; RIBEIRO, A. O; PUREZA, J. R; LISBOA, C. S. M. - Fundamentos e aplicações da Terapia Cognitivo-Comportamental com crianças e adolescentes - Revista Brasileira de Psicoterapia, 2014; I6(I): 85-103. Disponível em: http://rbp.celg.org.br/detalhe_artigo.asp?id=I44. Acesso em: 24 abr. 2021.

UNESCO. Coalizão Global de Educação, 2020. Disponível em: https://pt.unesco.org/covidig/educationresponse/globalcoalition. Acesso em: II mar. 202I.

UNESCO. Garantir o direito à educação inclusiva de qualidade para pessoas com deficiência: do compromisso à ação. Children With Disabilities. 2020. Disponível em: https://en.unesco.org/news/ensuring-right-quality-inclusive-education-personsdisabilities-commitment-action. Acesso em: 02 abr. 2021.

VYGOTSKY, Levy S. Pensamento e linguagem. São Paulo: Martins Fontes, 1987. (Coleção Psicologia e Pedagogia). 
VYGOTSKY, Levy S. A formação social da mente: o desenvolvimento dos processos psicológicos superiores. $3^{\mathrm{a}}$.ed. São Paulo: Martins Fontes, 1989. (Coleção Psicologia e Pedagogia. Nova Série).

ZANONATO, A; PRADO, L. C. Trabalhando com crianças e suas famílias: histórias terapêuticas. Porto Alegre: Editora Pallotti; 2012. 